\title{
Retracted: Folic acid supplementation, dietary folate intake during pregnancy and risk for spontaneous preterm delivery: a prospective observational cohort study
}

Verena Sengpiel ${ }^{1 *}$, Jonas Bacelis ${ }^{1}$, Ronny Myhre², Solveig Myking ${ }^{2}$, Aase Devold Pay ${ }^{3}$, Margaretha Haugen ${ }^{4}$, Anne-Lise Brantsæter ${ }^{4}$, Helle Margrete Meltzer ${ }^{4}$, Roy M Nilsen ${ }^{5}$, Per Magnus ${ }^{6}$, Stein Emil Vollset ${ }^{7}$,

Staffan Nilsson ${ }^{8}$ and Bo Jacobsson ${ }^{1,2}$

A retraction article was published for this article. It is available from the following link; http://www.biomedcentral. com/1471-2393/14/202.

\begin{abstract}
Background: Health authorities in numerous countries recommend periconceptional folic acid to pregnant women to prevent neural tube defects. The objective of this study was to examine the association of folic acid supplementation during different periods of pregnancy and of dietary folate intake with the risk of spontaneous preterm delivery (PTD).

Methods: The Norwegian Mother and Child Cohort Study is a population-based prospective cohort study. A total of 65,668 women with singleton pregnancies resulting in live births in 1999-2009 were included. Folic acid supplementation was self-reported from 26 weeks before pregnancy until week 24 during pregnancy. At gestational week 22, the women completed a food frequency questionnaire, which allowed the calculation of their average total folate intake from foods and supplements for the first 4-5 months of pregnancy. Spontaneous PTD was defined as the spontaneous onset of delivery between weeks $22^{+0}$ and $36^{+6}(n=1,628)$.
\end{abstract}

Results: The median total folate intake was $266 \mu \mathrm{g} / \mathrm{d}$ (interquartile range IQR 154-543) in the overall population and $540 \mathrm{\mu g} / \mathrm{d}$ (IQR 369-651) in the supplement users. Eighty-three percent reported any folic acid supplementation from $<8$ weeks before to 24 weeks after conception while $42 \%$ initiated folic acid supplementation before their pregnancy. Cox regression analysis showed that the amount of folate intake from the diet (hazard ratio HR 1.16; confidence interval $\mathrm{Cl} 0.65-2.08$ ) and from the folic acid supplements ( $\mathrm{HR} 1.04 ; \mathrm{Cl} 0.95-1.13$ ) was not significantly associated with the risk of PTD. The initiation of folic acid supplementation more than 8 weeks before conception was associated with an increased risk for PTD (HR 1.19; Cl 1.05-1.34) compared to no folic acid supplementation pre-conception. There was no significant association with PTD when supplementation was initiated within 8 weeks pre-conception ( $\mathrm{HR} 1.01 ; \mathrm{Cl}$ 0.88-1.16). All analyses were adjusted for maternal characteristics and socioeconomic, health and dietary variables.

Conclusions: Our findings do not support a protective effect of dietary folate intake or folic acid supplementation on spontaneous PTD. Pre-conceptional folic acid supplementation starting more than 8 weeks before conception was associated with an increased risk of PTD. These results require further investigation before discussing an expansion of folic acid supplementation guidelines.

Keywords: Pregnancy, Preterm delivery, Preterm birth, Gestational length, Folate, Folic acid supplementation

\footnotetext{
*Correspondence: verena.sengpiel@obgyn.gu.se

'Department of Obstetrics and Gynaecology, Sahlgrenska Academy,

Sahlgrenska University Hospital/Östra, SE-416 85 Göteborg, Sweden

Full list of author information is available at the end of the article
} 


\section{Background}

Folate is a B-vitamin essential for one-carbon metabolism and takes part in amino acid metabolism as well as DNA synthesis, repair and methylation [1,2]. Women are especially susceptible to folate deficiency during pregnancy, which is a period of rapid fetal growth, organ differentiation and high rates of cell division [1,3,4]. Since the 1950s, folic acid supplementation has been known to prevent megaloblastic anemia during pregnancy [5]. In the 1990s, large randomized trials demonstrated that peri-conceptional folic acid supplementation can prevent neural tube defects (NTD) in the newborn infant [6-8]. Today, national health authorities in many countries recommend periconceptional folic acid supplementation, and some countries have introduced mandatory folate fortification of foods $[1,3,4,9,10]$. In Norway, folic acid supplementation of $400 \mu \mathrm{g} / \mathrm{d}$ is recommended from the time of planning a pregnancy to gestational week $12[2,11]$, as is a daily folate intake of $500 \mu \mathrm{g} / \mathrm{d}$. This is in line with the Nordic Nutrition Recommendations [2].

Maternal folate status has also been associated with other adverse pregnancy outcomes such as preeclampsia, malformations such as orofacial clefts, spontaneous abortion, fetal death, fetal growth restriction and preterm delivery (PTD), although these results still remain inconclusive [1].

PTD, defined by the World Health Organization (WHO) as birth occurring before 37 weeks of gestation, is considered a major global health problem and is strongly associated with neonatal mortality as well as short- and long-term morbidity [12-14]. Spontaneous PTD is a common, complex condition with a prevalence of approximately $7 \%$ in the Norwegian population [15]. However, the effect of any single environmental factor is difficult to measure without largescale studies [15]. Modern obstetrics are still not able to predict, prevent or treat PTD [16]. Progesterone substitution, the only promising intervention identified to date, has been shown to reduce the chance of spontaneous PTD in highrisk pregnancies, but such cases account for only a small proportion of all pregnancies [17-19].

In the past decade, some observational studies have found that folic acid supplementation reduces the risk of PTD [20-22]. In some studies, this effect has been documented with an extended folic acid supplementation scheme or dosage compared with schemes based on NTD prevention, e.g., pre-conceptional folic acid supplementation for one year or longer [21] or thirdtrimester folic acid supplementation [22]. The most recent Cochrane review, based on data from 21 studies including one of the largest randomized controlled trials (RCT), as well as a recent meta-analysis of all RCTs published to date, could not confirm any effect of the maternal folate status on the gestational length or the risk of spontaneous PTD [23,24]. The comparability and generalizability of these earlier studies, which focused on the association of folate status and folic acid supplementation with pregnancy outcome, is limited because folic acid supplementation was assessed without considering other folate sources, the study populations had different levels of dietary folate intake, inadequate sample sizes, limited adjustment for important confounders, and/or retrospective study designs with folate data collection only after delivery $[1,4]$. Although PTD is a heterogeneous pregnancy outcome with different etiologies (early vs. late or iatrogenic vs. spontaneous), previous studies have mostly treated PTD as one entity, obscuring the differences in risk among PTD subtypes [25].

The Norwegian Mother and Child Cohort Study (MoBa) can meet a number of these challenges in study design, a requirement for addressing the inconsistencies in the field. MoBa includes 106,707 pregnancies, enabling the investigation of common complex pregnancy outcomes such as PTD. A detailed prospective assessment of folic acid supplementation starting from 6 months before conception throughout the pregnancy period, data regarding dietary folate intake and comprehensive information about lifestyle habits, health and socioeconomic status provide a unique opportunity to study the association between folate intake and PTD. For example, the effect of folic acid supplementation can be compared between women with low and high dietary folate intakes. By taking into account the amount of dietary folate and folic acid supplementation during different periods of pregnancy, it might be possible to define the folic acid supplementation scheme most likely to affect PTD.

The aim of this study was to examine the association of maternal folate intake from both supplemental and dietary sources with the risk of spontaneous PTD, with sub-analyses of early and late spontaneous PTD. The association of folic acid supplementation with PTD was studied in a stratified sample of women with low and high dietary folate intakes $(</ \geq 170 \mu \mathrm{g} / \mathrm{d})$.

\section{Methods}

\section{Study population}

The dataset is part of the MoBa cohort, initiated by and maintained at the Norwegian Institute of Public Health [15]. In brief, MoBa is a nation-wide pregnancy cohort that has included more than 106,000 pregnancies in the years from 1999 to 2009. The women were recruited through a postal invitation in connection with a routine ultrasound examination offered to all pregnant women in Norway approximately 17 weeks of gestation. Overall, $38.5 \%$ of the invited women participated. They were asked to fill in questionnaires focused on overall health status, lifestyle behavior and diet at gestational weeks 15-17 (Q1) and 30 (Q3). At week 22, they completed a food frequency questionnaire (FFQ). All questionnaires 
are available from the homepage of the Norwegian Institute of Public Health [26]. The present study used data from version 5 of the quality-assured data files made available for research in 2010. The MoBa database is linked to pregnancy and birth records from the Medical Birth Registry of Norway (MBRN) [27]. Informed written consent was obtained from each participant. The Regional Committee for Medical Research and the Norwegian Data Inspectorate approved the study.

Of 106,707 pregnancies included in the MoBa version 5, 103,921 pregnancies resulted in live-born singletons. Complete data for all 3 questionnaires including information about folate intake were available for 89,032 pregnancies. Women reporting improbable energy intakes of $<4.5 \mathrm{MJ}$ or $>20 \mathrm{MJ}$ were excluded [28], leaving 87,565 pregnancies. After exclusion of women with diabetes mellitus, hypertension, autoimmune diseases, inflammatory bowel diseases, systemic lupus erythematosus, rheumatoid arthritis, scleroderma, other immune-compromised conditions and those that underwent in-vitro fertilization, as well as those with pregnancy-related complications such as preeclampsia, hypertension, gestational diabetes, placental abruption, placenta previa, cervical cerclage and serious fetal malformations, 75,916 pregnancies were included in the study. Pregnancies with a gestational length of $<22^{+0}$ or $>42^{+6}$ weeks were excluded from further analysis, leaving 75,718 remaining. If a woman participated for more than one pregnancy, only her first pregnancy enrolled was included, leaving 65,668 pregnancies for analyses.

\section{Outcome}

The gestational age in days was determined with a secondtrimester ultrasound in $98.3 \%$ of the pregnancies and was based on the last menstrual period in the remaining cases. Spontaneous PTD was defined as birth after preterm labor or pre-labor rupture of the membranes between $22^{+0}$ and $36^{+6}$ weeks. Spontaneous PTD subgroups for early $\left(22^{+0}\right.$ $\left.33^{+6}\right)$ and late $\left(34^{+0}-36^{+6}\right)$ PTD were analyzed.

\section{Exposure}

\section{Amount of folate intake}

The amount of folate intake was calculated from the MoBa FFQ, a semi-quantitative questionnaire designed to yield information regarding the dietary habits and intake of dietary supplements during the first 5 months of pregnancy. The questionnaires were read optically, and the nutrient and energy intakes were calculated using FoodCalc [29] and the Norwegian Food Composition Table [30]. For the calculation of nutrients in the dietary supplements, an Access database (Microsoft Office 2003) containing the nutrient values of more than 1,000 dietary supplements was created and continuously updated. Dietary supplements commonly sold in Norway were registered based on information provided by the respective manufacturer, whereas nutritional information concerning dietary supplements bought from the Internet or abroad were obtained from the manufacturer's or supplier's homepage. A data program connected to the Access database read all food supplements recorded by the MoBa participants. The process of extracting dietary and supplement data is described in detail elsewhere [31,32].

Dietary folate was defined as $60 \%$ of the reported folate intake from foods, as only approximately $60 \%$ may be biologically accessible in comparison to that from the synthetic folic acid in supplements [1,3]. The total folate intake was thus calculated as supplemental folic acid + $0.6 \times$ folate intake from foods.

The daily folate intake was also categorized into 4 groups: $<170 \mu \mathrm{g} / \mathrm{d}$ (corresponding to the earlier WHO recommendation for all women to prevent anemia $[10,33])$, $170-500 \mu \mathrm{g} / \mathrm{d}$ (corresponding to the current Nordic Nutrition Recommendations for pregnant women for the prevention of NTDs [2]), 500-1000 $\mu \mathrm{g} / \mathrm{d}$ (corresponding to the tolerable upper limit for folic acid [2]) and $>1000 \mu \mathrm{g} / \mathrm{d}$.

\section{Time of folic acid supplementation}

The women reported their folic acid supplement use from 26 weeks before conception until gestational week 24 in 4-week intervals, including the period and frequency of supplementation. A woman was defined as a folic acid supplement user if she reported folic acid supplementation more than once a week in a registered 4-week period. Folic acid could be consumed either in the form of a folic acid supplement or as part of multivitamins. The most commonly used folic acid supplements for pregnant women in Norway contain $400 \mu \mathrm{g}$ of folic acid, while the most commonly used multivitamin supplements contain $200 \mu \mathrm{g}$ of folic acid. For this study, the start of folic acid supplementation was categorized as start during 26-9 weeks before conception, start during 8-0 weeks before conception, and no pre-conceptional folic acid supplementation.

\section{Covariates}

Information regarding the maternal age at delivery as well as the child's sex is available from the MBRN. Parity was based on data from both the MoBa and MBRN and categorized according to the number of previous pregnancies of $\geq 22^{+0}$ weeks' duration. Marital status was defined as either married/cohabitant or not. The self-reported prepregnancy heights and weights were used to calculate the pre-pregnancy body mass index (BMI) and were grouped according to the WHO classification as underweight $\left(<18.5 \mathrm{~kg} / \mathrm{m}^{2}\right)$, normal $\left(18.5-24.9 \mathrm{~kg} / \mathrm{m}^{2}\right)$, overweight $\left(25.0-29.9 \mathrm{~kg} / \mathrm{m}^{2}\right)$ and obese $\left(\geq 30.0 \mathrm{~kg} / \mathrm{m}^{2}\right)$. Maternal education was categorized as $\leq 12 \mathrm{y}, 13-16 \mathrm{y}$ and $\geq 17 \mathrm{y}$. The history of previous PTD at $22^{+0}-36^{+6}$ weeks of gestation, 
as well as the history of spontaneous abortion as registered in the MBRN, were taken into account as dichotomous variables. Women reported smoking habits during pregnancy in Q1 and were categorized as non-smokers, occasional or daily smokers. The alcohol intake from different sources was self-reported in the FFQ (glasses/d, week or month) and calculated as $\mathrm{g} / \mathrm{d}$. The household income was classified as both the participant and her partner having $<300,000$ Norwegian Kroner $(\mathrm{NOK}) / \mathrm{y}$, as either the participant or her partner having $\geq 300,000 \mathrm{NOK} / \mathrm{y}$ or as the participant and her partner both having $\geq 300,000 \mathrm{NOK} / \mathrm{y}$. Vitamin A supplementation was registered and categorized in the same manner as described for folic acid. These variables were used as a proxy for multivitamin supplementation, as there are no products on the Norwegian market containing vitamin $\mathrm{A}$ alone, and vitamin $\mathrm{A}$ is part of all common multivitamin preparations. In MoBa more than $99 \%$ of the participants are of Caucasian ethnicity; hence, ethnicity was not a relevant confounder.

\section{Statistical methods}

All statistical analyses were performed using IBM SPSS Statistics 19.0 and R 2.13.1 software. Total dietary folate intake from foods and supplements (median (IQR)) in relation to the maternal characteristics was studied with the Kruskal-Wallis test. The start of folic acid supplementation in relation to the maternal characteristics was studied with Pearson's chi-squared test. The association of total dietary folate intake and spontaneous PTD was estimated as a hazard ratio (HR) with a 95\% confidence interval (CI) by using Cox regression both in an unadjusted model and adjusted for the above-mentioned covariates. In these models, the event was defined as a spontaneous PTD; all iatrogenic deliveries and deliveries after the preterm $\left(\geq 37^{+0}\right.$ weeks) or early preterm $\left(\geq 34^{+0}\right.$ weeks) period were censored. The proportional hazards assumption was investigated by testing and inspecting scaled Schoenfeld residuals using $\mathrm{R}$ function cox.zph [34]. Statistical significance was assumed for 2-sided p-values of $<0.05$.

\section{Results}

Folate intake and folic acid supplementation in the study population

The median total dietary folate intake during the first five months of pregnancy and start of folic acid supplementation according to maternal characteristics are presented in Table 1. Dietary folate intake was higher in women who were older, did not smoke, had normal BMI (18.5-24.9 $\left.\mathrm{kg} / \mathrm{m}^{2}\right)$, who were having their first child, were married/cohabitant, who had higher education levels and family incomes. Women having experienced PTD, as well as women with a history of spontaneous abortion, had significantly lower total folate intakes. While women with a history of spontaneous abortion had more often started folic acid supplementation early, no comparable pattern in women with a history of PTD was found (Table 1).

Figure 1 illustrates the pattern of folic acid supplementation in the study population compared to vitamin A supplementation (as a proxy for multivitamin consumption) over the course of pregnancy. $83 \%$ of all women in the study reported folic acid supplementation at some point before and/or during pregnancy (Figure 1). While $42 \%$ began folic acid supplementation prior to conception, nearly $75 \%$ used supplements containing folic acid in the first trimester with decreasing use towards the end of pregnancy. At the same time, vitamin A supplementation was much more stable over the whole length of the pregnancy. The folic acid content of the reported supplements varied considerably, with only 2 women consuming folic acid amounts of $>5000 \mu \mathrm{g} / \mathrm{d}, 575 \mathrm{con}-$ suming $>1000 \mu \mathrm{g} / \mathrm{d}(1 \%), 6,160$ consuming $>500 \mu \mathrm{g} / \mathrm{d}$ (9\%), 9,589 consuming $>400 \mu \mathrm{g} / \mathrm{d}(15 \%), 24,337$ consuming $>200 \mu \mathrm{g} / \mathrm{d}(37 \%)$ and 30,708 consuming $>100 \mu \mathrm{g} / \mathrm{d}$ (47\%). Among supplement users, the median daily folic acid supplementation was $400 \mu \mathrm{g} / \mathrm{d}$ (interquartile range IQR 200-429). As presented in Table 2, folic acid from supplements was the main folate source in supplement users, while the main source was dietary folate in the whole population. There is no mandatory folate fortification of foods in Norway, and only $0.4 \%(n=272)$ of the study population reached the Nordic Nutrition Recommendation of $500 \mu \mathrm{g} / \mathrm{d}$ with their dietary folate intake $(2.8 \%, \mathrm{n}=1,854$, if the dietary folate was not adjusted for bio-availability). Of the study participants, $31 \%, n=20,369$, achieved the recommended levels with their total folate intake $(39.6 \%, \mathrm{n}=26,015$, if the dietary folate was not adjusted for bio-availability).

\section{Folate intake from different sources and risk for spontaneous PTD}

The median gestational age in this study population was 282 days (IQR 245-288), with 2,236 cases of PTD and 1,628 cases of spontaneous PTD. Of these, 264 babies were delivered before $34^{+0}$ weeks of gestation. Thus the PTD rate in our study population is $3.4 \%$, approximately half of the PTD rate in the general Norwegian population as we excluded all risk-pregnancies due to maternal disease, pregnancy-complications or fetal malformation.

There was no significant association between the amount of folate intake from the diet or supplements and the risk of spontaneous PTD (Table 3). Likewise, no association was found when the total folate intake was categorized according to the former WHO recommendation for women $(>170 \mu \mathrm{g} / \mathrm{d})$, the current Nordic Nutrition Recommendations for pregnant women $(>500 \mu \mathrm{g} / \mathrm{d})$ and the tolerable upper limit for folic acid supplementation $(<1000$ $\mu \mathrm{g} / \mathrm{d})$ (Additional file 1: Table S1). Cox regression for the 
Table 1 Folate variables and maternal characteristics

\begin{tabular}{|c|c|c|c|c|c|c|c|c|c|c|c|c|c|}
\hline \multirow[b]{3}{*}{ Total } & & \multirow{3}{*}{$\begin{array}{c}n \\
65668\end{array}$} & \multirow{3}{*}{$\begin{array}{l}(\%) \\
(100)\end{array}$} & \multicolumn{3}{|c|}{ Total folate intake $(\mu \mathrm{g} / \mathrm{d})$} & \multicolumn{7}{|c|}{ Initiation of preconceptional folic acid supplementation, $n$ (\%) } \\
\hline & & & & \multicolumn{2}{|c|}{ median (IQR) } & \multirow[t]{2}{*}{$p^{1}$} & \multicolumn{2}{|c|}{$>8 w$} & \multicolumn{2}{|c|}{$0-8 w$} & \multicolumn{2}{|c|}{ no } & \multirow[t]{3}{*}{$p^{2}$} \\
\hline & & & & 266 & $(153-543)$ & & 15471 & (24) & 12308 & (19) & 37889 & $(58)$ & \\
\hline & $<25$ & 7583 & $(12)$ & 228 & $(143-504)$ & & 842 & (11) & 879 & $(12)$ & 5862 & $(77)$ & \\
\hline Maternal age & $25-29$ & 22745 & (35) & 275 & $(154-547)$ & $<0.0001$ & 4990 & (22) & 4605 & $(20)$ & 13150 & (58) & $<0.0001$ \\
\hline \multirow[t]{2}{*}{ in years } & $30-34$ & 27782 & $(42)$ & 270 & $(155-546)$ & & 7475 & (27) & 5662 & $(20)$ & 14645 & (53) & \\
\hline & $>34$ & 7558 & $(12)$ & 276 & $(160-547)$ & & 2164 & (29) & 1162 & (15) & 4232 & (56) & \\
\hline Pre- & $<18.5$ & 2004 & (3) & 294 & $(160-554)$ & & 439 & (22) & 344 & $(17)$ & 1221 & $(61)$ & \\
\hline pregnancy & $18.5-24.9$ & 43198 & (66) & 278 & $(157-549)$ & $<0.0001$ & 10611 & (25) & 8388 & (19) & 24199 & $(56)$ & $<0.0001$ \\
\hline BMl in & $25-30$ & 13448 & (21) & 248 & $(148-533)$ & & 2999 & (22) & 2483 & (18) & 7966 & (59) & \\
\hline \multirow[t]{4}{*}{$\mathrm{kg} / \mathrm{m} 2$} & $\geq 30$ & 5341 & (8) & 229 & $(141-515)$ & & 1146 & (21) & 822 & (15) & 3373 & (63) & \\
\hline & missing & 1677 & (3) & 226 & $(144-491)$ & & 276 & (16) & 271 & $(16)$ & 1130 & $(67)$ & \\
\hline & 0 & 33501 & $(51)$ & 320 & $(165-566)$ & & 8753 & (26) & 6031 & $(18)$ & 18717 & $(56)$ & \\
\hline & 1 & 20743 & (32) & 233 & $(146-526)$ & $<0.0001$ & 4581 & (22) & 4466 & $(22)$ & 11696 & $(56)$ & $<0.0001$ \\
\hline \multirow[t]{3}{*}{ Parity } & 2 & 9199 & (14) & 211 & $(144-480)$ & & 1752 & (19) & 1525 & $(17)$ & 5922 & $(64)$ & \\
\hline & $3+$ & 2140 & (3) & 200 & (140-388) & & 370 & (17) & 272 & (13) & 1498 & (70) & \\
\hline & missing & 85 & $(0,1)$ & 183 & $(121-401)$ & & 15 & (18) & 14 & $(16)$ & 56 & $(66)$ & \\
\hline Marital & yes & 63134 & (96) & 268 & $(154-544)$ & $<0.0001$ & 15184 & (24) & 12101 & (19) & 35849 & (57) & $<0.0001$ \\
\hline status & no & 2534 & (4) & 232 & $(147-493)$ & & 287 & (11) & 207 & (8) & 2040 & $(81)$ & \\
\hline Maternal & $<13$ & 20618 & $(31)$ & 214 & $(138-483)$ & & 3237 & (16) & 2774 & (13) & 14607 & (71) & \\
\hline education & $13-16$ & 27249 & $(41)$ & 291 & $(157-553)$ & $<0.0001$ & 6841 & (25) & 5601 & $(21)$ & 14807 & (54) & $<0.0001$ \\
\hline in & $>16$ & 16415 & (25) & 331 & $(171-569)$ & & 5096 & (31) & 3718 & $(23)$ & 7601 & $(46)$ & \\
\hline years & missing & 1386 & (2) & 243 & $(144-528)$ & & 297 & (21) & 215 & $(16)$ & 874 & $(63)$ & \\
\hline History of & no & 63433 & (97) & 267 & $(154-543)$ & $<0.0001$ & 14980 & (24) & 11879 & (19) & 36574 & $(58)$ & 0.18 \\
\hline preterm & yes & 2155 & (3) & 237 & $(151-521)$ & & 472 & (22) & 411 & (19) & 1272 & (59) & \\
\hline delivery & missing & 80 & $(0,1)$ & 252 & $(144-554)$ & & 19 & (24) & 18 & $(23)$ & 43 & $(54)$ & \\
\hline History of & no & 53123 & $(81)$ & 269 & $(154-544)$ & $<0.0001$ & 11655 & (22) & 10112 & (19) & 31356 & (59) & $<0.0001$ \\
\hline \multirow[t]{2}{*}{ abortion } & yes & 12545 & (19) & 251 & $(150-540)$ & & 3816 & (30) & 2196 & (18) & 6533 & $(52)$ & \\
\hline & never & 59678 & (91) & 277 & $(156-548)$ & & 14752 & (25) & 11691 & (20) & 33235 & $(56)$ & \\
\hline Smoking & occasionally & 1879 & (3) & 218 & $(141-453)$ & $<0.0001$ & 255 & (14) & 231 & $(12)$ & 1393 & (74) & $<0.0001$ \\
\hline \multirow[t]{2}{*}{ habits } & daily & 3733 & (6) & 190 & $(128-390)$ & & 399 & (11) & 319 & (9) & 3015 & $(81)$ & \\
\hline & missing & 378 & (1) & 221 & $(140-451)$ & & 65 & (17) & 67 & (18) & 246 & $(65)$ & \\
\hline Alcohol & no alcohol & 55368 & (84) & 289 & $(159-551)$ & & 13360 & (24) & 10672 & (19) & 31336 & (57) & \\
\hline
\end{tabular}


Table 1 Folate variables and maternal characteristics (Continued)

\begin{tabular}{|c|c|c|c|c|c|c|c|c|c|c|c|c|c|}
\hline consumption & $<0.5$ & 6565 & (10) & 245 & $(150-528)$ & $<0.0001$ & 1403 & (21) & 1162 & (18) & 4000 & $(61)$ & $<0.0001$ \\
\hline in units/week & $\geq 0.5$ & 3735 & (6) & 149 & $(117-209)$ & & 708 & (19) & 474 & (13) & 2553 & $(68)$ & \\
\hline Partners with & 0 & 19439 & $(30)$ & 225 & $(143-507)$ & $<0.0001$ & 3246 & (17) & 2853 & (15) & 13340 & (69) & \\
\hline income of & 1 & 26938 & $(41)$ & 265 & $(154-542)$ & & 6287 & (23) & 5253 & (20) & 15398 & $(57)$ & $<0.0001$ \\
\hline$>300,000$ & 2 & 17472 & $(27)$ & 337 & $(169-572)$ & & 5687 & (33) & 3939 & (23) & 7846 & $(45)$ & \\
\hline NOK/year & missing & 1819 & (3) & 227 & $(147-511)$ & & 251 & (14) & 263 & (14) & 1305 & $(72)$ & \\
\hline Baby's & male & 33445 & (51) & 262 & $(152-541)$ & 0.003 & 7875 & (24) & 6198 & (19) & 19372 & (58) & 0.3 \\
\hline sex & female & 32223 & (49) & 270 & $(155-545)$ & & 7596 & (24) & 6110 & (19) & 18517 & $(57)$ & \\
\hline Tertiles of & 1 & 21890 & (33) & 179 & $(115-503)$ & & 5251 & (24) & 4031 & (18) & 12608 & (58) & \\
\hline energy intake & 2 & 21890 & (33) & 263 & $(155-548)$ & $<0.0001$ & 5397 & (25) & 4307 & (20) & 12186 & $(56)$ & $<0.0001$ \\
\hline in $M J$ & 3 & 21888 & (33) & 325 & $(203-591)$ & & 4823 & (22) & 3970 & (18) & 13095 & $(60)$ & \\
\hline
\end{tabular}

Amount of total daily folate intake (FFQ data) and initiation of folic acid supplementation (Q1 data) according to maternal characteristics, from 65,668 participants in the Norwegian Mother and Child Cohort Study

$(2002-2009)$.
1 p-value, estimated with Kruskal-Wallis test.

p-value, estimated with Pearson's chi-squared test. 
sub-groups of early and late spontaneous PTD did not reveal any significant associations between the folate intake and pregnancy outcome (not shown). Testing the proportional hazards assumptions revealed a slight misfit for the parity variable. Therefore all analyses were also run with stratified Cox regression using parity as strata. The changes from the unstratified analyses were however marginal and did not change any pattern or conclusion.

\section{Initiation of folic acid supplementation and risk for spontaneous PTD}

The initiation of folic acid supplementation more than 8 weeks before conception was associated with a marginally increased risk of spontaneous PTD also after adjusting for potential confounders (Table 4 and Additional file 2: Figure S1a; HR 1.19; confidence interval CI 1.05-1.34). The initiation of supplementation more than 8 weeks before conception was significantly associated with early $\left(<34^{+0}\right.$ weeks) but not late spontaneous PTD (Additional file 3: Figure S1b) however the difference in HR was not significant. After stratification for the total dietary folate intake from foods, the initiation of folic acid supplementation more than 8 weeks before conception was significantly associated with an increased risk of spontaneous PTD for those women with low dietary folate intakes (HR 1.22; CI 1.04-1.45). The interaction between dietary folate intake and initiation of supplementation was not significant, though. The same association was found in the subgroup of early but not late spontaneous PTD (Additional file 4: Table S2).

A history of earlier adverse pregnancy outcomes could be a motive for the early initiation of folic acid supplementation in subsequent pregnancies. However, the analysis of the subgroup of primi-gravidae $(\mathrm{n}=23,919,36 \%)$ showed the same overall results, with even larger HRs for the early initiation of folic acid supplementation (HR 1.32; CI 1.111.57).

The early initiation of folic acid supplementation could characterize women that planned a pregnancy but did not become pregnant during the first months, thus including a subgroup of sub-fertile women [35]. In MoBa, the women were asked to report the number of months with regular intercourse without contraception before becoming pregnant, and these data were classified as follows: $<1$ month $(\mathrm{n}=12,912,20 \%), 1-2$ months $(\mathrm{n}=14,818,23 \%)$ and $>2$ months $(\mathrm{n}=21,883,33 \%)$. Stratification for this variable still showed increased HRs for the early initiation of folic acid supplementation in the subgroup that became pregnant within the first month (HR 1.39; CI 1.02-1.89), again with larger HRs for the subgroup with early PTD (HR 2.32; CI 1.20-4.48).

\section{Pregnancy period of folic acid supplementation and risk for spontaneous PTD}

The time of folic acid supplementation was represented by four variables corresponding to the following periods: $26-9$ weeks before conception, $0-8$ weeks before conception, first trimester and second trimester. If the Cox regression included all of the confounders and the outcome of spontaneous PTD was analyzed, the prediction of the model improved after introducing all four folic acid supplementation variables $(p=0.005)$. Folic acid supplement use more than 8 weeks pre-conception was associated with an increased HR for spontaneous PTD, even after adjusting for the supplementation at all other time points studied

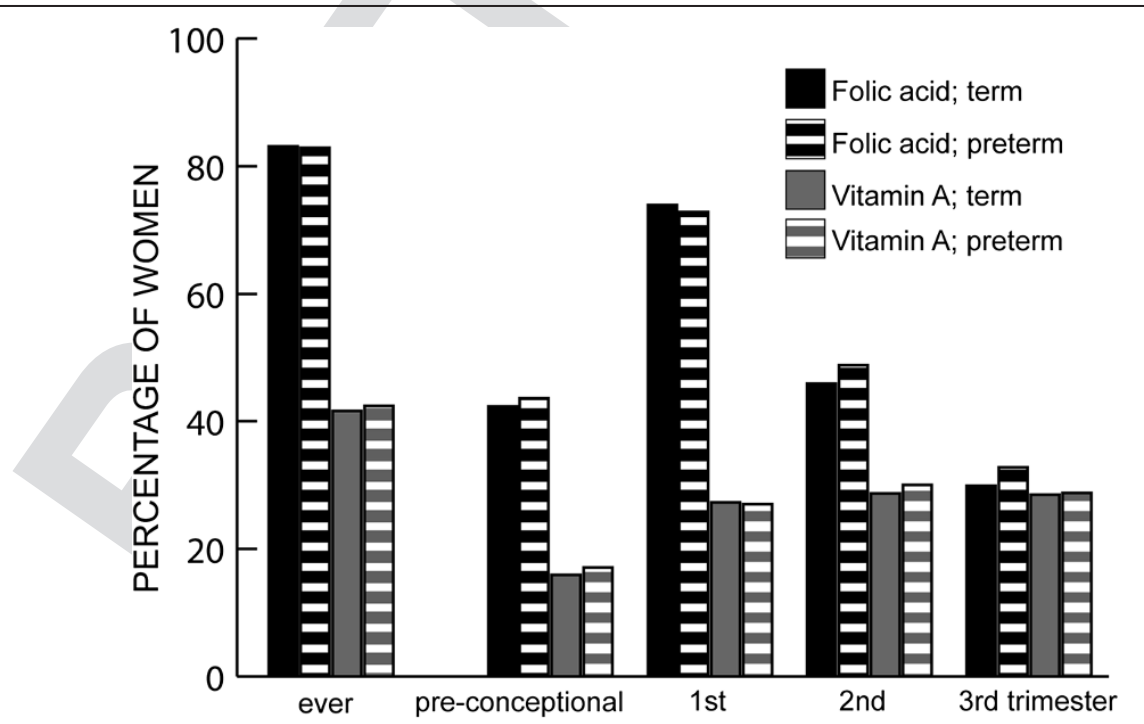

Figure 1 Prevalence of folic acid and vitamin A supplementation during pregnancy. Prevalence of folic acid and vitamin A supplementation during pregnancy (Q1 and Q3 data) in women with spontaneous term or preterm delivery $\left(22^{+0}-36^{+6}\right.$ weeks, $\left.n=1,628\right)$ among 65,668 participants in the Norwegian Mother and Child Cohort Study (2002 - 2009). 
Table 2 Folate intake from diet and supplements

\begin{tabular}{|c|c|c|c|c|c|c|}
\hline \multirow[b]{2}{*}{ Folate $(\mu \mathrm{g} / \mathrm{d})$} & \multicolumn{2}{|c|}{ All } & \multicolumn{2}{|c|}{ Spontaneous term delivery } & \multicolumn{2}{|c|}{ Spontaneous PTD ${ }^{1}$} \\
\hline & Median & IQR & Median & $\mathrm{IQR}$ & Median & IQR \\
\hline All women & \multicolumn{2}{|c|}{$n=65668$} & \multicolumn{2}{|c|}{$n=50301$} & \multicolumn{2}{|c|}{$n=1628$} \\
\hline Diet & 155 & $(123-193)$ & 155 & $(123-193)$ & 155 & $(123-194)$ \\
\hline Supplements & 67 & $(0-400)$ & 57 & $(0-400)$ & 100 & $(0-400)$ \\
\hline Total intake & 266 & $(154-543)$ & 262 & $(153-542)$ & 280 & $(154-557)$ \\
\hline Supplement users & \multicolumn{2}{|c|}{$\mathrm{n}=35510$} & \multicolumn{2}{|c|}{$n=27007$} & \multicolumn{2}{|c|}{$n=891$} \\
\hline Diet & 158 & $(127-196)$ & 158 & $(127-196)$ & 159 & $(128-197)$ \\
\hline Supplements & 400 & $(200-429)$ & 400 & $(200-429)$ & 400 & $(200-457)$ \\
\hline Total intake & 530 & $(354-636)$ & 530 & $(354-635)$ & 540 & $(369-651)$ \\
\hline
\end{tabular}

Folic acid supplementation, dietary and total folate intake during the first half of pregnancy (FFQ data) for all 65,668 participants, as well as in folic acid supplement users $(n=35,510)$, from the Norwegian Mother and Child Cohort Study (2002-2009).

Preterm delivery defined as delivery between $22^{+0}-36^{+6}$ weeks of gestation.

(Table 5). The marginally significant association with decreased HRs for first-trimester supplementation was no longer significant if the model was adjusted for vitamin A supplementation (data not shown).

\section{Discussion}

In this large prospective national birth cohort study, we did not find any statistically significant association between the amount of folate intake from the diet or supplements and spontaneous PTD in uncomplicated pregnancies. Folic acid supplementation starting more than 8 weeks before conception was associated with an increased HR for spontaneous PTD.

When interpreting the results, the selection of the study population has to be kept in mind: all known risk-pregnancies due to maternal disease, pregnancy complications or fetal malformation have been excluded from the analysis. There might be an association between the amount of folate intake from diet or supplements and spontaneous PTD in those pregnancies excluded.

Table 3 Folate intake from different sources and risk of spontaneous preterm delivery (PTD)

\begin{tabular}{lcccccc}
\hline & \multicolumn{3}{c}{ Unadjusted } & \multicolumn{3}{c}{ Adjusted $^{2}$} \\
\hline Folate $(\mu \mathrm{g} / \mathrm{d})$ & $\mathrm{HR}^{1}$ & $(\mathrm{Cl})$ & $\mathrm{P}$ & $\mathrm{HR}^{1}$ & $(\mathrm{Cl})$ & $\mathrm{P}$ \\
Diet & 1.10 & $(0.73-1.66)$ & 0.66 & 1.16 & $(0.65-2.08)$ & 0.61 \\
Supplements & 1.06 & $(0.97-1.16)$ & 0.17 & 1.04 & $(0.95-1.13)$ & 0.43 \\
Total intake & 1.06 & $(0.98-1.15)$ & 0.16 & 1.04 & $(0.95-1.14)$ & 0.39 \\
\hline
\end{tabular}

Amount of folic acid supplementation, dietary and total folate intake (FFQ data) and hazard ratios for spontaneous PTD $\left(22^{+0}-36^{+6}\right.$ weeks, $\left.n=1,628\right)$. Cox regression for 65,668 participants in the Norwegian Mother and Child Cohort Study (2002-2009). latrogenic deliveries have been censored in the regression model.

${ }^{1}$ HR per $500 \mu \mathrm{g}$ extra folate/d.

${ }^{2}$ Cox regression, adjusted for maternal age, prepregnancy BMI, parity, history of PTD and spontaneous abortion, child's sex, smoking habits and alcohol consumption during pregnancy, maternal education, marital status, household income, energy intake. Mutual adjustment for dietary and supplemental folate intake.
Our results, demonstrating no significant protective effect of the maternal folate intake or folic acid supplementation on the spontaneous PTD risk, support a number of earlier observational studies [36-41] and RCTs [6,42,43]. A reanalysis of the most recent Cochrane review, based on data from 21 studies and one of the largest RCTs as well as a recent meta-analysis of all RCTs published to date, could not confirm the effect of the maternal folate status on the gestational length or risk of PTD [23,24]. Shaw et al. found a comparable association of increased PTD risk and preconceptional folic acid supplementation when analyzing data from the US National Birth Defects Study [41]. In addition, extensive supplementation with multivitamins with a major folic acid component was associated with an increased risk of PTD in a study by Alwan et al. [36].

However, some recent observational studies have found that folic acid supplementation reduces the risk of PTD [20-22]. In some cases, this association was linked to preconceptional folic acid supplementation for 1 year or longer [21] or third-trimester folic acid supplementation [22], raising questions about extended supplementation schemes compared to the NTD prevention scheme. A protective effect of folic acid supplementation was supported by a modest reduction in the PTD rate after the introduction of folate fortification of foods [9].

One of the most obvious explanations for these conflicting results could be the dosage of folic acid. While most of the studies finding an association with gestational length or PTD were based on comparably high doses of folic acid $(\geq 5000 \mu \mathrm{g} / \mathrm{d}[20,22,44], \geq 2500 \mu \mathrm{g} / \mathrm{d}[22,45]$ and $\geq 500$ $\mu \mathrm{g} / \mathrm{d}$ [46-48]), very few women in our study population consumed as much as $5000 \mu \mathrm{g} / \mathrm{d}$ of supplemental folic acid, while only $9 \%$ consumed $>500 \mu \mathrm{g} / \mathrm{d}$ and $15 \%$ consumed $>400 \mu \mathrm{g} / \mathrm{d}$. However, the Hungarian RCT, one of the biggest performed so far, did not find any effect of a high dosage of $8000 \mu \mathrm{g} / \mathrm{d}$ of folic acid supplementation on PTD [6]. Unfortunately, the folic acid dosage was not indicated in all of the studies $[21,35]$. 
Table 4 Initiation of pre-conceptional folic acid supplementation and risk of spontaneous preterm delivery (sPTD)

\begin{tabular}{|c|c|c|c|c|c|c|c|c|c|c|c|}
\hline \multirow[t]{2}{*}{ SPTD } & \multicolumn{2}{|l|}{ Initiation of folic acid } & \multicolumn{3}{|c|}{ Unadjusted } & \multicolumn{3}{|c|}{ Adjusted $^{1}$} & \multicolumn{3}{|c|}{ Adjusted $^{2}$} \\
\hline & supplementation & $\mathrm{n}$ & $\mathrm{HR}$ & $(\mathrm{Cl})$ & $p$ & $\mathrm{HR}$ & $(\mathrm{Cl})$ & $\mathrm{p}$ & $\mathrm{HR}$ & $(\mathrm{Cl})$ & $\mathrm{p}$ \\
\hline & No & 919 & 1 & & & 1 & & & 1 & & \\
\hline \multirow[t]{3}{*}{ All } & 0-8 w preconceptional & 281 & 0.94 & $(0.82-1.07)$ & 0.36 & 1.01 & $(0.88-1.16)$ & 0.91 & 1.02 & $(0.88-1.17)$ & 0.82 \\
\hline & $>8$ w preconceptional & 428 & 1.14 & $(1.02-1.28)$ & 0.02 & 1.19 & $(1.05-1.34)$ & 0.01 & 1.19 & $(1.04-1.35)$ & 0.01 \\
\hline & No & 139 & 1 & & & 1 & & & 1 & & \\
\hline \multirow[t]{3}{*}{ Early } & 0-8 w preconceptional & 46 & 1.02 & $(0.73-1.42)$ & 0.92 & 1.15 & $(0.82-1.62)$ & 0.43 & 1.10 & $(0.77-1.57)$ & 0.59 \\
\hline & >8 w preconceptional & 79 & 1.39 & $(1.06-1.84)$ & 0.02 & 1.53 & $(1.14-2.04)$ & 0.004 & 1.45 & $(1.05-1.99)$ & 0.02 \\
\hline & No & 780 & 1 & & & 1 & & & 1 & & \\
\hline \multirow[t]{2}{*}{ Late } & 0-8 w preconceptional & 235 & 0.93 & $(0.8-1.07)$ & 0.30 & 0.98 & $(0.85-1.14)$ & 0.83 & 1.00 & $(0.86-1.17)$ & 0.98 \\
\hline & >8 w preconceptional & 349 & 1.10 & $(0.97-1.25)$ & 0.14 & 1.13 & $(0.99-1.29)$ & 0.07 & 1.14 & $(0.99-1.32)$ & 0.07 \\
\hline
\end{tabular}

The assessment of folate intake from supplementation alone or when studying populations with different dietary folate intakes are additional factors compromising comparability and generalizability between studies. While recent US studies are performed against the background of mandatory folate fortification of food [21,41], other studies have examined supplementation effects in folate-deficient populations [44]. Few studies have assessed the effects of both dietary folate and folic acid supplementation separately [41] or combined [20,47,49], and adjustments for bioavailability are rare. In this Norwegian study population, only $0.4 \%$ of the participants reached the Nordic Nutrition
Recommendation of $500 \mu \mathrm{g} / \mathrm{d}$ with their dietary folate intake (adjusted with a factor of 0.6 for bioavailability; $2.8 \%$ without adjustment), and $31 \%$ of the participants achieved the recommended level with their total folate intake $(39.6 \%$ without adjustment). After stratification for dietary folate intake, the early initiation of folic acid supplementation was significantly associated with spontaneous PTD in the subgroup of women with low but not high dietary folate intakes. There were no significant associations between high total folate intakes and PTD risk in the MoBa study population.

Confounding is always an issue when assessing the effect of a single environmental factor on a complex

Table 5 Timing of folic acid supplementation and risk of spontaneous preterm delivery (sPTD)

\begin{tabular}{|c|c|c|c|c|c|c|c|c|}
\hline sPTD & Time of olic acid & & & Unadjusted & & & Adjusted $^{1}$ & \\
\hline \multirow{5}{*}{ All } & supplementation & $n$ & $\mathrm{HR}$ & $(\mathrm{Cl})$ & $\mathrm{p}$ & $H R$ & $(\mathrm{Cl})$ & $\mathrm{p}$ \\
\hline & $>8$ w pre-conceptional & 428 & 1.16 & $(1.04-1.30)$ & 0.01 & 1.16 & $(1.02-1.31)$ & 0.02 \\
\hline & 0-8 w pre-conceptional & 572 & 1.02 & $(0.93-1.13)$ & 0.64 & 1.04 & $(0.92-1.17)$ & 0.52 \\
\hline & 1st trimester & 1185 & 0.94 & $(0.84-1.05)$ & 0.25 & 0.88 & $(0.78-0.99)$ & 0.04 \\
\hline & 2nd trimester & 795 & 1.11 & $(1.01-1.23)$ & 0.03 & 1.10 & $(0.99-1.21)$ & 0.08 \\
\hline \multirow{3}{*}{ Early } & >8 w pre-conceptional & 79 & 1.39 & $(1.07-1.80)$ & 0.01 & 1.34 & $(0.99-1.80)$ & 0.06 \\
\hline & 0-8 w pre-conceptional & 103 & 1.21 & $(0.94-1.55)$ & 0.13 & 1.18 & $(0.88-1.58)$ & 0.26 \\
\hline & 1st trimester & 199 & 1.07 & $(0.81-1.42)$ & 0.62 & 0.94 & $(0.69-1.28)$ & 0.67 \\
\hline \multirow{5}{*}{ Late } & 2nd trimester & 137 & 1.26 & $(0.99-1.60)$ & 0.06 & 1.18 & $(0.91-1.51)$ & 0.21 \\
\hline & >8 w pre-conceptional & 349 & 1.12 & $(0.99-1.27)$ & 0.07 & 1.13 & $(0.98-1.29)$ & 0.09 \\
\hline & 0-8 w pre-conceptional & 469 & 0.99 & $(0.89-1.11)$ & 0.88 & 1.01 & $(0.89-1.15)$ & 0.84 \\
\hline & 1st trimester & 986 & 0.91 & $(0.81-1.03)$ & 0.14 & 0.87 & $(0.76-0.99)$ & 0.04 \\
\hline & 2nd trimester & 658 & 1.09 & $(0.98-1.21)$ & 0.13 & 1.08 & $(0.97-1.21)$ & 0.17 \\
\hline
\end{tabular}

Folic acid supplementation at different times (Q1 and Q3 data) and hazard ratios for spontaneous PTD $\left(n=1,628\right.$ for $22^{+0}-36^{+6}$ weeks, $n=264$ for early $\left(22^{+0}-33^{+6}\right)$, $n=1,364$ for late $\left(34^{+0}-36^{+6}\right)$ ). Cox regression for 65,668 participants in the Norwegian Mother and Child Cohort Study (2002 - 2009). latrogenic deliveries have been censored in the regression model.

${ }^{1}$ Cox regression, adjusted for maternal age, prepregnancy BMI, parity, history of PTD and spontaneous abortion, child's sex, smoking habits and alcohol consumption during pregnancy, maternal education, marital status, household income, energy intake and dietary folate intake. Mutual adjustment for folic acid supplementation at other time points. 
outcome like PTD. For example, it is well established that women with high levels of education, privileged socioeconomic status and healthier overall diets are more likely to use supplements during pregnancy [50,51] and less likely to experience PTD than women without these characteristics. Some observational studies failed to adjust for these confounders, and the effect attributed to folic acid supplementation might in fact be confounded by overall health and lifestyle behaviors. While the strength of the significance was moderate, the association with the early onset of folic acid supplementation in the current study remained significant even after extensive adjustment for maternal characteristics such as socioeconomic and life-style parameters as well as obstetric anamnesis.

Associations with the early start of supplementation should be studied with particular caution. The early start of folic acid supplementation might partially identify a group of women with a history of adverse pregnancy outcomes who want to optimize conditions for their current pregnancy. As presented in Table 1, women who had previously experienced spontaneous abortions were more likely to initiate folic acid supplementation early in their subsequent pregnancies. However, the same association of the early initiation of folic acid supplementation and spontaneous PTD was found in primi-gravidae. Folic acid supplementation starting more than 8 weeks prior to conception might characterize women who planned a pregnancy but did not become pregnant during their first 2 cycles, thus constituting a subgroup of women with suboptimal fertility [35]. The same association of the early start of supplementation was found in the group of women that became pregnant within the first month. Women who choose to start early with folic acid supplementation might be distinguished by some other characteristic that could be the causal link to spontaneous preterm delivery so that we cannot exclude confounding.

In addition to the amount of folic acid, the composition of supplements is another point of discussion. In some countries like Greece and Norway, commonly used supplements contain folic acid and/or iron only [20]. In other countries, folic acid is mainly consumed in the form of multivitamins, making it difficult to differentiate the effects of multivitamin use and folic acid supplementation $[21,35,41,48]$. Vitamins other than folic acid might explain the association between multivitamin use and PTD. Catov et al. found that in the Danish birth cohort, multivitamin use was associated with modestly decreased PTD rates, while there was no association with folic acid supplementation [37]. As seen from Figure 1, vitamin A consumption (as a proxy for multivitamin supplementation) differed considerably from folic acid supplementation. However, the MoBa FFQ allowed us to calculate folic acid separately from other supplements, and adjusting for vitamin A consumption did not change the results for pre-conceptional folic acid supplementation.

Apart from the amount, timing and composition of folate exposure, differences in the definition of pregnancy outcomes hinder comparability. Most studies defined PTD as delivery at $<37^{+0}$ weeks of gestation without indicating the range of gestational age. This information might be important, especially if the risk of early PTD is found to be associated with folate status, as suggested by this study and that of Bukowski et al. [21]. Although PTD is a heterogeneous pregnancy outcome with distinct etiologies for different subgroups [25], not all studies analyzed clearly defined subgroups such as spontaneous PTD $[20,21,37,40,47,52]$.

\section{Strengths and weaknesses}

With a sample size of 65,668 pregnancies, this was a wellpowered study for investigating the association of folate intake and pregnancy outcomes. Due to the large study sample, there were 1,628 cases defined as spontaneous PTD and 264 and 1,364 cases in the subgroups of early and late spontaneous PTD, respectively. The estimation of the gestational length by the second-trimester ultrasounds and the definition of a clear spontaneous PTD phenotype distinguishes this study [25].

The MoBa participation rate is $38.5 \%$, and a demographic comparison with the MBRN in 2002 showed that single women and women $<25$ y of age are underrepresented in MoBa. Regarding PTD (7.2\% in MoBa and 7.7\% in MBRN), the differences are minor, and even the subgroup composition is similar to the distribution in the total population, with spontaneous PTD accounting for $42 \%$ of all PTD [15]. Additionally, a recent study found no bias in 8 selected exposure-outcome associations [53].

The assessment of folate from both the diet and supplements is a clear strength of this study. Although all dietary assessment methods have limitations, the MoBa FFQ has been extensively validated in a sub-population of $119 \mathrm{MoBa}$ participants using a 4-day weighed food diary and biological markers in the blood and urine as reference measures [54]. The dietary supplement use was evaluated specifically. The total folate intake by the FFQ showed good agreement with the folate intake detailed by the food diary and was significantly reflected by the serum folate concentrations [31]. In a subsample of an earlier MoBa version (2934 singleton pregnancies), Nilsen et al. did not find any significant associations of dietary folate intake, folic acid supplementation or plasma folate with PTD. This study also reported good agreement between the folate intake (dietary and supplements) by the MoBa FFQ and plasma folate concentration $(r=0.44, C I$ : $0.41-0.47)$ [38]. As the relevant window of susceptibility for folate effects regarding pregnancy outcomes other than NTD is not yet known, the assessment of folate intake at different time points is a further strength of this study. The prospective design 
ensured that the women's answers were not influenced by their knowledge of pregnancy outcomes.

\section{Conclusions}

The amount of dietary folate and supplemental folic acid intake in uncomplicated 65,668 singleton pregnancies from the Norwegian Mother and Child Cohort Study was not associated with a risk of spontaneous PTD, at least not at the relatively low intake levels of dietary folate (median $155 \mu \mathrm{g} / \mathrm{d}$ corrected for bio-availability, uncorrected $258 \mu \mathrm{g} / \mathrm{d}$ ) and supplemental folic acid (median $400 \mu \mathrm{g} / \mathrm{d}$ ) in this healthy study population.

The initiation of folic acid supplementation more than 8 weeks prior to conception was associated with an increased risk for overall and early spontaneous PTD in both the overall analyses and in the strata of women with low dietary folate intake.

Even if MoBa allows adjustment for a variety of confounders, the presence of residual confounding cannot be ruled out. However, our results require careful investigation regarding dosage and timing of folic acid supplementation, such as in the form of an RCT, before discussing a change of the current guidelines.

\section{Additional files}

Additional file 1: Table S1. Folate intake according to official

recommendations and risk of spontaneous PTD.

Additional file 2: Figure S1a. Initiation of pre-conceptional folic acid supplementation and risk of spontaneous PTD. Initiation of preconceptional folic acid supplementation (Q1 data) and cumulative risk of spontaneous PTD $\left(22^{+0}-36^{+6}\right.$ weeks, $\left.n=1,628\right)$. Cox regression for 65,668 participants in the Norwegian Mother and Child Cohort Study (2002 2009), adjusted for maternal age, prepregnancy BMI, parity, history of PTD and spontaneous abortion, child's sex, smoking habits and alcohol consumption during pregnancy, maternal education, marital status, household income, energy intake and dietary folate intake. latrogenic deliveries have been censored in the regression model.

Additional file 3: Figure 1b. Initiation of pre-conceptional folic acid supplementation and risk of early spontaneous PTD. Initiation of preconceptional folic acid supplementation (Q1 data) and cumulative risk of early spontaneous PTD $\left(22^{+0}-33^{+6}\right.$ weeks, $\left.\mathrm{n}=264\right)$. Cox regression for 65,668 participants in the Norwegian Mother and Child Cohort Study (2002 - 2009), adjusted for maternal age, prepregnancy BMl, parity, history of PTD and spontaneous abortion, child's sex, smoking habits and alcohol consumption during pregnancy, maternal education, marital status, household income, energy intake and dietary folate intake. latrogenic deliveries have been censored in the regression model.

Additional file 4: Table S2. Initiation of pre-conceptional folic acid supplementation and risk of spontaneous preterm delivery (SPTD), depending on dietary folate intake.

\section{Abbreviations}

BMl: Body mass index; Cl: Confidence interval; FFQ: Food frequency questionnaire; HR: Hazard ratio; IQR: Interquartile range; MoBa: The norwegian mother and child cohort study; MBRN: Medical birth registry of norway; NOK: Norwegian crowns, currency; NTD: Neural tube defect; PTD: Preterm delivery; Q1, Q3: Questionnaire 1, 3; RCT: Randomized controlled trial; WHO: World health organization.
Competing interests

The authors declare that they have no competing interests.

\section{Authors' contributions}

All authors planned the study. VS, JB and SN analyzed the data. VS, RM, SM, BJ selected preterm deliveries. MH calculated on folate intake from Q2. All authors contributed with interpretation of results and writing of the paper. All authors have read and approved the final manuscript.

\section{Acknowledgments}

We are grateful to all families in Norway who are participating in this ongoing cohort study.

Statement of financial support: This work was supported by grants from the Norwegian Research Council (FUGE 183220/S10, FRIMEDKLI-05 ES236011), the Swedish Medical Society (SLS 2008-21198) and Swedish government grants to researchers in public health service (ALFGBG-2863, ALFGBG-11522). The funders had no role in study design, data collection and analysis, decision to publish, or preparation of the manuscript.

\section{Author details}

'Department of Obstetrics and Gynaecology, Sahlgrenska Academy, Sahlgrenska University Hospital/Östra, SE-416 85 Göteborg, Sweden. ${ }^{2}$ Department of Genes and Environment, Division of Epidemiology, Norwegian Institute of Public Health, P.O. Box 4404, Nydalen, NO-0403 Oslo, Norway. ${ }^{3}$ Department of Obstetrics, Oslo University Hospital, P.O. Box 4950, Nydalen, NO-0424 Oslo, Norway. ${ }^{4}$ Department of Exposure and Risk Assessment, Division of Environmental Medicine, Norwegian Institute of Public Health, P.O. Box 4404, Nydalen, NO-0403 Oslo, Norway. ${ }^{5}$ Department of Public Health and Primary Health Care, University of Bergen, NO-5018 Bergen, Norway. ${ }^{6}$ Division of Epidemiology, Norwegian Institute of Public Health, P.O. Box 4404, NO-0403 Oslo, Norway. ${ }^{7}$ Norwegian Institute of Public Health and University of Bergen, Kalfarveien 31, NO-5018 Bergen, Norway.

${ }^{8}$ Mathematical Sciences, Chalmers University of Technology, SE-412 96 Göteborg, Sweden.

Received: 8 February 2013 Accepted: 5 August 2013

Published: 12 August 2013

\section{References}

1. Tamura T, Picciano MF: Folate and human reproduction. Am J Clin Nutr 2006, 83:993-1016

2. Nordic Council of Ministers: Folate. In Nordic Nutrition Recommendations 2004 Integrating nutrition and physical activity. Copenhagen: Norden; 2004:287-296.

3. World Health Organization; Food and Agricultural Organization of the United Nations: Folate and Folic acid. In Vitamin and mineral requirements in human nutrition. Rome: FAO; 2004:53-62.

4. Scholl TO, Johnson WG: Folic acid: influence on the outcome of pregnancy. Am J Clin Nutr 2000, 71(5 Suppl):1295S-1303S.

5. Israels MC, Da Cunha FA: Megaloblastic anaemia of pregnancy. Lancet 1952, 2:214-215.

6. Czeizel AE, Dudas I, Metneki J: Pregnancy outcomes in a randomised controlled trial of periconceptional multivitamin supplementation. Final report. Arch Gynecol Obstet 1994, 255:131-139.

7. Czeizel $A E$, Dudas I: Prevention of the first occurrence of neural-tube defects by periconceptional vitamin supplementation. The New England journal of medicine 1992, 327:1832-1835.

8. MRC Vitamin Study Research Group: Prevention of neural tube defects: results of the Medical Research Council Vitamin Study. Lancet 1991, 338:131-137.

9. Shaw GM, Carmichael SL, Nelson V, Selvin S, Schaffer DM: Occurrence of low birthweight and preterm delivery among California infants before and after compulsory food fortification with folic acid. Public Health Rep 2004, 119:170-173.

10. de Bree A, van Dusseldorp M, Brouwer IA, van het Hof KH, SteegersTheunissen RP: Folate intake in Europe: recommended, actual and desired intake. Eur J Clin Nutr 1997, 51:643-660.

11. Kostholdsråd gravide (Dietary recommendation for pregnant women, in Norwegian). http://www.helsedirektoratet.no/folkehelse/ernering/ kostholdsrad/gravide/Sider/default.aspx. 
12. WHO Expert Committee: The prevention of perinatal mortality and morbidity. Report of a WHO Expert Committee. World Health Organ Tech Rep Ser 1970, 457:1-60

13. Moster D, Lie RT, Markestad T: Long-term medical and social consequences of preterm birth. N Engl J Med 2008, 359:262-273.

14. Bryce J, Boschi-Pinto C, Shibuya K, Black RE: WHO estimates of the causes of death in children. Lancet 2005, 365:1147-1152.

15. Magnus P, Irgens LM, Haug K, Nystad W, Skjaerven R, Stoltenberg C: Cohort profile: the Norwegian Mother and Child Cohort Study (MoBa). Int $J$ Epidemiol 2006, 35:1146-1150.

16. Lockwood CJ: Predicting premature delivery-no easy task. N Engl J Med 2002, 346:282-284.

17. Hassan SS, Romero R, Vidyadhari D, Fusey S, Baxter JK, Khandelwal M, Vijayaraghavan J, Trivedi Y, Soma-Pillay P, Sambarey P, Dayal A, Potapov V, O'Brien J, Astakhov V, Yuzko O, Kinzler W, Dattel B, Sehdev H, Mazheika L, Manchulenko D, Gervasi MT, Sullivan L, Conde-Agudelo A, Phillips JA, Creasy GW: Vaginal progesterone reduces the rate of preterm birth in women with a sonographic short cervix: a multicenter, randomized, double-blind, placebo-controlled trial. Ultrasound in obstetrics \& gynecology : the official journal of the International Society of Ultrasound in Obstetrics and Gynecology 2011, 38:18-31

18. Dodd JM, Flenady VJ, Cincotta R, Crowther CA: Progesterone for the prevention of preterm birth: a systematic review. Obstet Gynecol 2008, 112:127-134.

19. Romero R, Nicolaides K, Conde-Agudelo A, Tabor A, O'Brien JM, Cetingoz E, Da Fonseca E, Creasy GW, Klein K, Rode L, Soma-Pillay P, Fusey S, Cam C, Alfirevic Z, Hassan SS: Vaginal progesterone in women with an asymptomatic sonographic short cervix in the midtrimester decrease preterm delivery and neonatal morbidity: a systematic review and metaanalysis of individual patient data. American journal of obstetrics and gynecology 2012, 206:124. e121-119.

20. Papadopoulou E, Stratakis N, Roumeliotaki T, Sarri K, Merlo DF, Kogevinas M, Chatzi L: The effect of high doses of folic acid and iron supplementation in early-to-mid pregnancy on prematurity and fetal growth retardation: the mother-child cohort study in Crete, Greece (Rhea study). European journal of nutrition 2013 52: 327-336.

21. Bukowski R, Malone FD, Porter FT, Nyberg DA, Comstock CH, Hankins GD, Eddleman K, Gross SJ, Dugoff L, Craigo SD, Timor-Tritsch IE, Carr SR, Wolfe HM, D'Alton ME: Preconceptional folate supplementation and the risk of spontaneous preterm birth: a cohort study. PLOS Med 2009, 6:e1000061

22. Czeizel AE, Puho EH, Langmar Z, Acs N, Banhidy F: Possible association of folic acid supplementation during pregnancy with reduction of preterm birth: a population-based study. European journal of obstetrics, gynecology, and reproductive biology 2010, 148:135-140.

23. Charles DH, Ness AR, Campbell D, Smith GD, Whitley E, Hall MH: Folic acid supplements in pregnancy and birth outcome: re-analysis of a large randomised controlled trial and update of Cochrane review. Paediatr Perinat Epidemiol 2005, 19:112-124.

24. Fekete K, Berti C, Trovato M, Lohner S, Dullemeijer C, Souverein OW, Cetin I, Decsi T: Effect of folate intake on health outcomes in pregnancy: a systematic review and meta-analysis on birth weight, placental weight and length of gestation. Nutrition journal 2012, 11:75.

25. Pennell CE, Jacobsson B, Williams SM, Buus RM, Muglia L, Dolan SM Morken NH, Ozcelik H, Lye SJ, Relton C: Genetic epidemiologic studies of preterm birth: guidelines for research. American journal of obstetrics and gynecology 2007, 196:107-118.

26. Norwegian Mother and Child Study. http://www.fhi.no/eway/default.aspx?

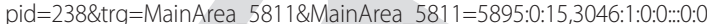

27. Irgens LM: The Medical Birth Registry of Norway. Epidemiological research and surveillance throughout 30 years. Acta Obstet Gynecol Scand 2000, 79:435-439.

28. Meltzer HM, Brantsaeter AL, Ydersbond TA, Alexander J, Haugen M: Methodological challenges when monitoring the diet of pregnant women in a large study: experiences from the Norwegian Mother and Child Cohort Study (MoBa). Matern Child Nutr 2008, 4:14-27.

29. Lauritzen J: FoodCalc. www.ibt.ku.dk/jesper/FoodCalc/Default.htm.

30. Norwegian Food Safety Authority, Norwegian Directorate of Health, Department of Nutrition - University of Oslo: Matvaretabellen (The Norwegian Food Table, in Norwegian). http://www.matvaretabellen.no/.

31. Brantsaeter AL, Haugen M, Hagve TA, Aksnes L, Rasmussen SE, Julshamn K, Alexander J, Meltzer HM: Self-reported dietary supplement use is confirmed by biological markers in the Norwegian Mother and Child Cohort Study (MoBa). Ann Nutr Metab 2007, 51:146-154.

32. Haugen M, Brantsaeter AL, Alexander J, Meltzer HM: Dietary supplements contribute substantially to the total nutrient intake in pregnant Norwegian women. Ann Nutr Metab 2008, 52:272-280.

33. FAO/WHO Expert Consultation: Requirements of Vitamin A, Iron, Folate and Vitamin B12 Report of a Joint FAO/WHO Expert Consultation (FAO Fisheries Report). World Health Organization, Rome; 1988.

34. Grambsch PM, Therneau TM: Proportional hazards tests and diagnostics based on weighted residuals. Biometrika 1994, 81:515-526.

35. Callaway L, Colditz PB, Fisk NM: Folic acid supplementation and spontaneous preterm birth: adding grist to the mill? PLoS Med 2009, 6:e1000077.

36. Alwan NA, Greenwood DC, Simpson NA, McArdle HJ, Cade JE: The relationship between dietary supplement use in late pregnancy and birth outcomes: a cohort study in British women. BJOG : an international journal of obstetrics and gynaecology 2010, 117:821-829.

37. Catov JM, Bodnar LM, Olsen J, Olsen S, Nohr EA: Periconceptional multivitamin use and risk of preterm or small-for-gestational-age births in the Danish National Birth Cohort. The American journal of clinical nutrition 2011, 94:906-912.

38. Nilsen RM, Vollset SE, Monsen AL, Ulvik A, Haugen M, Meltzer HM, Magnus P, Ueland PM: Infant birth size is not associated with maternal intake and status of folate during the second trimester in Norwegian pregnant women. The Journal of nutrition 2010, 140:572-579.

39. Timmermans S, Jaddoe WW, Hofman A, Steegers-Theunissen RP, Steegers EA: Periconception folic acid supplementation, fetal growth and the risks of low birth weight and preterm birth: the Generation R Study. The British journal of nutrition 2009, 102:777-785

40. Dunlop AL, Taylor RN, Tangpricha V, Fortunato S, Menon R: Maternal Micronutrient Status and Preterm Versus Term Birth for Black and White US Women. Reproductive sciences 2012, 19:939-948.

41. Shaw GM, Carmichael SL, Yang W, Siega-Riz AM: Periconceptional intake of folic acid and food folate and risks of preterm delivery. American journal of perinatology 2011, 28:747-752.

42. Fleming AF, Martin JD, Stenhouse NS: Pregnancy anaemia, iron and folate deficiency in Western Australia. Med J Aust 1974, 2:479-484.

43. Fletcher J, Gurr A, Fellingham FR, Prankerd TA, Brant HA, Menzies DN: The value of folic acid supplements in pregnancy. J Obstet Gynaecol Br Commonw 1971, 78:781-785

44. Baumslag N, Edelstein T, Metz J: Reduction of incidence of prematurity by folic acid supplementation in pregnancy. Br Med J 1970, 1:16-17.

45. Rolschau J, Kristoffersen $K$, Ulrich M, Grinsted P, Schaumburg E, Foged N: The influence of folic acid supplement on the outcome of pregnancies in the county of Funen in Denmark. Part I. Eur J Obstet Gynecol Reprod Biol 1999, 87:105-110. discussion 103-104.

46. Scholl TO, Hediger ML, Bendich A, Schall JI, Smith WK, Krueger PM: Use of multivitamin/mineral prenatal supplements: influence on the outcome of pregnancy. Am J Epidemiol 1997, 146:134-141.

47. Siega-Riz AM, Savitz DA, Zeisel SH, Thorp JM, Herring A: Second trimester folate status and preterm birth. Am J Obstet Gynecol 2004 191:1851-1857.

48. Furness DL, Yasin N, Dekker GA, Thompson SD, Roberts CT: Maternal red blood cell folate concentration at 10-12 weeks gestation and pregnancy outcome. The journal of maternal-fetal \& neonatal medicine: the official journal of the European Association of Perinatal Medicine, the Federation of Asia and Oceania Perinatal Societies, the International Society of Perinatal Obstetricians 2012, 25:1423-1427.

49. Scholl TO, Hediger ML, Schall Jl, Khoo CS, Fischer RL: Dietary and serum folate: their influence on the outcome of pregnancy. Am J Clin Nutr 1996, 63:520-525.

50. Bailey RL, Dodd KW, Gahche JJ, Dwyer JT, McDowell MA, Yetley EA, Sempos CA, Burt VL, Radimer KL, Picciano MF: Total folate and folic acid intake from foods and dietary supplements in the United States: 2003-2006. The American journal of clinical nutrition 2010, 91:231-237.

51. Nilsen RM, Vollset SE, Gjessing HK, Magnus P, Meltzer HM, Haugen M, Ueland PM: Patterns and predictors of folic acid supplement use among pregnant women: the Norwegian Mother and Child Cohort Study. Am J Clin Nutr 2006, 84:1134-1141.

52. Bergen NE, Jaddoe WW, Timmermans S, Hofman A, Lindemans J, Russcher $H$, Raat H, Steegers-Theunissen RP, Steegers EA: Homocysteine and folate concentrations in early pregnancy and the risk of adverse pregnancy 
outcomes: the Generation R Study. BJOG : an international journal of obstetrics and gynaecology 2012, 119:739-751.

53. Nilsen RM, Vollset SE, Gjessing HK, Skjaerven R, Melve KK, Schreuder P, Alsaker ER, Haug K, Daltveit AK, Magnus P: Self-selection and bias in a large prospective pregnancy cohort in Norway. Paediatr Perinat Epidemiol 2009, 23:597-608.

54. Brantsaeter AL, Haugen M, Alexander J, Meltzer HM: Validity of a new food frequency questionnaire for pregnant women in the Norwegian Mother and Child Cohort Study (MoBa). Matern Child Nutr 2008, 4:28-43.

doi:10.1186/1471-2393-13-160

Cite this article as: Sengpiel et al:: Retracted: Folic acid supplementation, dietary folate intake during pregnancy and risk for spontaneous preterm delivery: a prospective observational cohort study. $B M C$ Pregnancy and Childbirth 2013 13:160.

\section{Submit your next manuscript to BioMed Central and take full advantage of:}

- Convenient online submission

- Thorough peer review

- No space constraints or color figure charges

- Immediate publication on acceptance

- Inclusion in PubMed, CAS, Scopus and Google Scholar

- Research which is freely available for redistribution 